\title{
Erratum to: Cardiovascular toxicity of anticancer-targeted therapy: emerging issues in the era of cardio-oncology
}

\author{
Emanuel Raschi · Fabrizio De Ponti
}

Published online: 21 February 2012

(C) SIMI 2012

\section{Erratum to: Intern Emerg Med}

\section{DOI 10.1007/s11739-011-0744-y}

In the original publication of this article, the word "inappropriate" was not spaced out in the last line of the abstract section by mistake. The sentence should read as follows:

In this scenario, onco-vigilance (i.e., pharmacovigilance oriented to oncologic drugs) is emerging as a key to support cardio-oncologists in appropriateness.

The online version of the original article can be found under doi:10.1007/s11739-011-0744-y.

E. Raschi · F. De Ponti $(\varangle)$

Department of Pharmacology, University of Bologna,

Via Irnerio 48, 40126 Bologna, BO, Italy

e-mail: fabrizio.deponti@unibo.it 